\title{
A Research on the trend of Total Amount and Structure of China Knowledge Innovation
}

\author{
Biao-hang Ma \\ College of Economics and Management, Sichuan Agricultural University \\ 211 Huimin Road, WenJiang District, Chengdu City, Sichuan Province 611130, China \\ Tel: 86-18980407045Ｅ-mail: mabiaohang@qq.com \\ Xun-gang Zheng (Corresponding author) \\ College of Economics and Management, Sichuan Agricultural University \\ 211 Huimin Road, WenJiang District, Chengdu City, Sichuan Province 611130, China \\ Tel: 86-15520735096 E-mail: zxg9@163.com
}

Accepted: July 01, 2013 Published: August 17, 2013

Doi:10.5296/ijld.v3i4.4318 URL: http://dx.doi.org/10.5296/ijld.v3i4.4318

\begin{abstract}
This article analyzes the tendency of total amount and structure of China knowledge innovation in the recently 18 years through the logarithm model, it discovers that the GDP has a relatively role in promoting the knowledge innovation, whereas the total population does not significantly positive impact on knowledge innovation. Based on the economic convergence theory of neoclassical growth theory and the classification of different subjects, this article establishes a theoretical analysis framework using dynamic panel data and discovers that the disciplinary differences of knowledge innovation presents $\sigma$-convergence, while the knowledge innovation presents absolute $\beta$-convergence in the medium and long term. Finally, this paper gives some advices for the sustainable development of the knowledge innovation.
\end{abstract}

Keywords: Knowledge Innovation, Logarithm Model, Dynamic Panel Data, Convergence

\section{Introduction}

With the explosive growth of knowledge and the intellectual property rights knowledge innovation exerts greater role in promoting economy along. At the same time, knowledge innovation is playing a vital role to improve the quality of people, eliminate the gap and build a harmonious society. Compared with the developed countries, the problems of overall lagging behind and unreasonable structure of knowledge innovation have aroused society's widespread attention in China. From the average, over the past decade (2000-2010), the patent quality of the world's major countries has felled by an average of $20 \%$ than on another ten-year (1990-2000). All countries tend to submit higher quality of patent applications to the foreign and less than a quarter of the patents succeed to market eventually. The reference rate of patent submitted by the inventor coming from the United States, Germany and Japan is the highest, but the patent citation level submitted by Chinese still lags behind that of developed countries and some developing countries. Based on this, China's 12th five-year plan clearly put forward 
the strategy of reinvigoration through innovation, science and education in China through human resource development. So, what kind of the development trend of China's total knowledge innovation? Is the influence on total knowledge innovation by the national economic and population significant influence? What is the knowledge innovation structure classified according to subject? In the current backdrop, answering these questions has an important guiding significance for promoting the China's innovation-driven, the implementing science and education strategy and reinvigorating China through human resource development.

Most scholars affirmed that the China knowledge innovation has a significant growth effect after China's reform and opening up. Zhou You (2012) who used the number of authorized patents as technological innovation, found that there was a relationship of mutual interaction between technological innovation and economic growth through an empirical analysis. It showed that China was on the way of high innovation but potential decline, although economic growth will slow down in a short term, but the technical innovation will move up the economy in the next 5 to 10 years. Ma Ji (2011) analyzed on the core elements of knowledge innovation based on associated knowledge of regional economic growth in the Spatial Economics and found that the intellectuals number represented by the number of college educated people has a higher impact on the growth of knowledge innovation in every region, but the region's population size or market share of knowledge was not a prominent role in promoting innovation. He also found that knowledge innovation has a significant positive correlation on regional economic growth, the level of economic growth has a positive interaction in the ability of knowledge innovation in every region. In these studies, the knowledge represented by the number of patented technologies and the efficiency of knowledge innovation industry, but the journal articles are the direct manifestation of knowledge innovation, so there is a flaw to measure the total knowledge innovation. Based on this, this article seeks to fill the problems in existing studies and make efforts in the following three aspects: Firstly, use the number of papers published in journals which included the Chinese core journals to measure the scale of China knowledge innovation last 18 years; Secondly, test whether the national economy and population have a significant impact on knowledge innovation or not; Thirdly, analyze whether there is a convergence characteristics or not between different disciplines empirically.

In summary, there are many points of penetration in research about the scale and structure of knowledge innovation. Although a differences of time span, economic models, econometric analysis methods and statistical caliber in researches, it came to different conclusions, the researches still have a practical significance and reference value. This paper mainly focuses on the total amount, structure of knowledge innovation and the relationship between them using regression analysis and convergence tests. On this basis, this paper also explained the theory combined with China's actual conduct and put forward countermeasures and suggestions.

\section{Variable selection and model specification}

\subsection{Selection of variables, data source and data processing}

The study of total knowledge innovation trends in China uses national annual data between 1994 and 2011 as shown in Table 1. The number of total papers comes from the amount of Chinese Core journals included by Chinese Journal Full-text Database (CJFD). The Chinese Core journals are subject to China Core Journals Particular Overview (Peking University Press). The macro data such as gross domestic product (GDP) is from China statistical yearbook (2012).

The study of trends of knowledge innovation structure used panel data of paper number of Chinese core journals included in CJFD sort by different subjects between 1994 and 2011. According to the subject, Chinese core journals will be divided into science and engineering A (mathematics, physics, mechanics, astronomy, geography, biology), science and engineering B 
(Chemistry, Chemical Industry, Metallurgy, Environmental Studies, mining industry), science and engineering C (Machine electricity, Aeronautics, Traffic, Water Conservation, Architecture, Energy), Agriculture, medicine and health care, social science (Literature, History, Philosophy), political science(Politics, Military, Law), Education, information science (Electronic, informatics) and Economics (Economics, Management), amount to 10 disciplines.

The data of GDP is adjusted by the CPI (1978 year $=100)$. $P N$ (Paper Number) represents the articles (an article), GDP represents gross domestic product (one hundred million RMB) and $H P$ (Human Population) represents year-end population (ten thousand people). At the same time, as the logarithmic transformation of variables, $L n P N, L n G D P$ and $L n H P$ represent articles, $G D P$ and year-end population after natural logarithmic transformation respectively.

Table 1. time series of Total Chinese core journals in CJFD, GDP and year-end population in 1994-2012

\begin{tabular}{|l|l|l|l|l|l|l|l|}
\hline year & $\begin{array}{l}\text { Papers } \\
\text { Number } \\
\text { /article }\end{array}$ & $\begin{array}{l}\text { Adjusted } \\
\text { GDP } \\
\text { /100Million } \\
\text { RMB }\end{array}$ & $\begin{array}{l}\text { Year-end } \\
\text { Population } \\
\text { /10thousand }\end{array}$ & year & $\begin{array}{l}\text { Papers } \\
\text { Number } \\
\text { /article }\end{array}$ & $\begin{array}{l}\text { Adjusted GDP } \\
\text { /100Million } \\
\text { RMB }\end{array}$ & $\begin{array}{l}\text { Year-end } \\
\text { Population } \\
\text { /10thousand }\end{array}$ \\
\hline 1994 & 290488 & 142.1765677 & 119850 & 2003 & 382703 & 309.6028178 & 129227 \\
\hline 1995 & 295003 & 153.1714014 & 121121 & 2004 & 457153 & 350.7642341 & 129988 \\
\hline 1996 & 247458 & 165.5654609 & 122389 & 2005 & 418482 & 398.5719159 & 130756 \\
\hline 1997 & 244113 & 178.7124576 & 123626 & 2006 & 512693 & 459.2662971 & 131448 \\
\hline 1998 & 250732 & 192.5234484 & 124761 & 2007 & 551890 & 538.5135856 & 132129 \\
\hline 1999 & 290433 & 207.4897148 & 125786 & 2008 & 14912 & 600.813903 & 132802 \\
\hline 2000 & 325204 & 228.6049638 & 126743 & 2009 & 317054 & 656.8454963 & 133450 \\
\hline 2001 & 330603 & 250.9271637 & 127627 & 2010 & 605292 & 748.3716255 & 134091 \\
\hline 2002 & 355849 & 277.5840583 & 128453 & 2011 & 595749 & 834.6265487 & 134735 \\
\hline
\end{tabular}

Data source: Papers number comes from CJFD (visiting Dec 20, 2012); GDP and year-end population come from Chinese Analytic Annual (2012).

It can be seen that the paper number appears an increasing trend year by year, but the paper number fell sharply over the past two years in 2008 and 2009, because CJFD database of core journal articles is not full in these two years. Since these two points belong to the extreme values, this article replaces these two points by the trend estimation of two years before-and-after. GDP comes from the national statistical yearbook and is adjusted by CPI. Correlation coefficients of $P N$ to $G D P$ and $H N$ are $0.9547,0.9136$ respectively. It is obvious they have strong correlations.

\section{2 specification of model}

\subsubsection{The changing trend research on China knowledge innovation}

The country's economic level as well as the size of population influence the knowledge innovation. Generally speaking, the Knowledge Innovation is higher in developed countries than developing countries. Population directly reflects the number of production and consumption of knowledge innovation, so the population's influence on knowledge innovation should not be neglected. Other variables and random factors were incorporated into the random variable $\mu$, establishing model as follows:

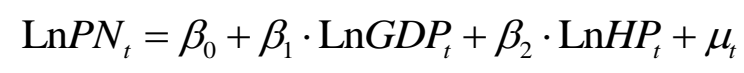

The subscript $t$ on the type stands for the time in year, paper number $P N$ on behalf of the knowledge innovation activity that reflects the high and low tide of the knowledge innovation, and the GDP reflects the economic boom and recession. 


\subsubsection{The trend research of China knowledge innovation structure}

For the trend study of China knowledge innovation structure, the paper uses the economic convergence of new classical economic growth theory, the data of core journal articles numbers of 10 different disciplines included in CJFD between 1994 to 2011. What's more, this paper constructs a dynamic panel model and empirically analyses whether there is convergence for different disciplines in China from the perspective of subject classification.

It is called sigma - convergence if the discrete degree of paper number in different subjects is reduced every year over a period of time. This article measures it by coefficient of variation $(\mathrm{CV})$ and the computation formula is as follows:

$$
C V_{t}=\frac{\delta_{t}}{\mu_{t}} \cdot 100 \% t=1,2,3,(T-1)
$$

Among them, the $\stackrel{\circ}{\mathrm{t}}_{\mathrm{t}}$ is the standard deviation of $P N$ of different disciplines publishing in the $t^{\text {th }}$ year, the ${ }^{-}{ }_{\mathrm{t}}$ is the average of $P N$ different disciplines publishing in the $\mathrm{t}^{\text {th }}$ year.

Over a period of time, if the $P N$ of a subject with lower initial value grows more quickly than the $P N$ with higher initial value and $P N$ renders the convergence between different subjects, the gap of the process is called beta convergence. This paper uses the simplified Barro absolute beta convergence of linear regression equation to test it.

$$
\ln \left(\frac{Y_{i, t+k}}{Y_{i, t}}\right)=c+\beta \cdot \ln Y_{i, t}, i=1,2,3,10 t=1,2,3,(T-k)
$$

Among them, $Y_{i, t}$ represents the $P N$ of the $i^{\text {th }}$ subject classification in the $t^{\text {th }}$ year,$Y_{i, t+k}$ represents the $P N$ of the $(i+k)^{\text {th }}$ subject classification in the $(t+k)^{\text {th }}$ year. If $\bullet<0$ (the beta is the estimated regression equation coefficient), it explains that the $P N$ is convergent in period $t$ to $t+k$, meaning that the knowledge innovation growth rate of the lag subject is higher than the developed subject. Subsequently, it makes the knowledge innovation structure leveled off.

\section{Empirical analysis}

\subsection{An empirical analysis of the trends of total knowledge innovation in China}

The logarithm model of $P N, G D P$ and $H P$ uses the ordinary least squares regression expression between 1994 and 2011 is as follows:

$$
{\mathrm{Ln} P N_{t}}_{t}=42.9458+0.7395 \cdot \mathrm{LnGDP}_{t}+2.9196 \cdot \mathrm{Ln} H P_{t}
$$

After $t$ test, the coefficient estimates of constant term and HP are not significant, therefore, it removes the HP variable and do the regression again, the expression as follows:

$$
{\mathrm{Ln} P N_{t}}=9.6299+0.5621 \cdot \mathrm{LnGDP}+0 \cdot \mathrm{Ln} H P_{t}
$$

Checked by White test, residual is heteroscedastic; Checked by DW test, residual is first order autocorrelation. Therefore, it uses weighted least squares estimate again, regression expression is as follows (the numbers in the square brackets under the estimated coefficients are the $t$ statistic):

$$
\begin{gathered}
\operatorname{Ln} P N_{t}=\underset{(174.2125)}{9.7105}+\underset{(56.4113)}{0.5483} \cdot \operatorname{Ln} G D P_{t}+0 \cdot \operatorname{Ln} H P_{t} \\
R^{2}=0.9950 \quad n=18 \quad D W=1.7290
\end{gathered}
$$

In the logarithmic model, the elasticity of $P N$ to $G D P$ is 0.5483 , meaning that $P N$ increased by $0.5483 \%$ with the growth of $1 \%$ GDP. The growth rate of knowledge innovation is lower than 
$G D P$, declaring that China should continue to increase economic input of knowledge innovation. China government released the compendium of Chinese education reform and development in 1993, firstly proposed a target that the expenditure of state financial education funds should reach 4\% of GDP at the end of the 20th century and achieve its goal in 2012. So it can be predicted that the elasticity of $P N$ to GDP will increase sharply.

In the model, it also can find that the factor of population have no significant impact on knowledge innovation, to some extent, demonstrating that a country with intellectual powers is not necessarily linked with the big population. Only adhering to the rejuvenation strategy of science and education, will the big population turn into intellectual powers?

\subsection{An empirical analysis of the trend of subject structure of the knowledge innovation in China}

\subsubsection{Sigma - convergence analysis}

It analyses the panel data of paper number from the core journals classified by subjects, figure 2 describes the dynamic process of coefficient of variation about 10 different discipline of core periodical publications in the database of CJFD from 1994 to 2011.

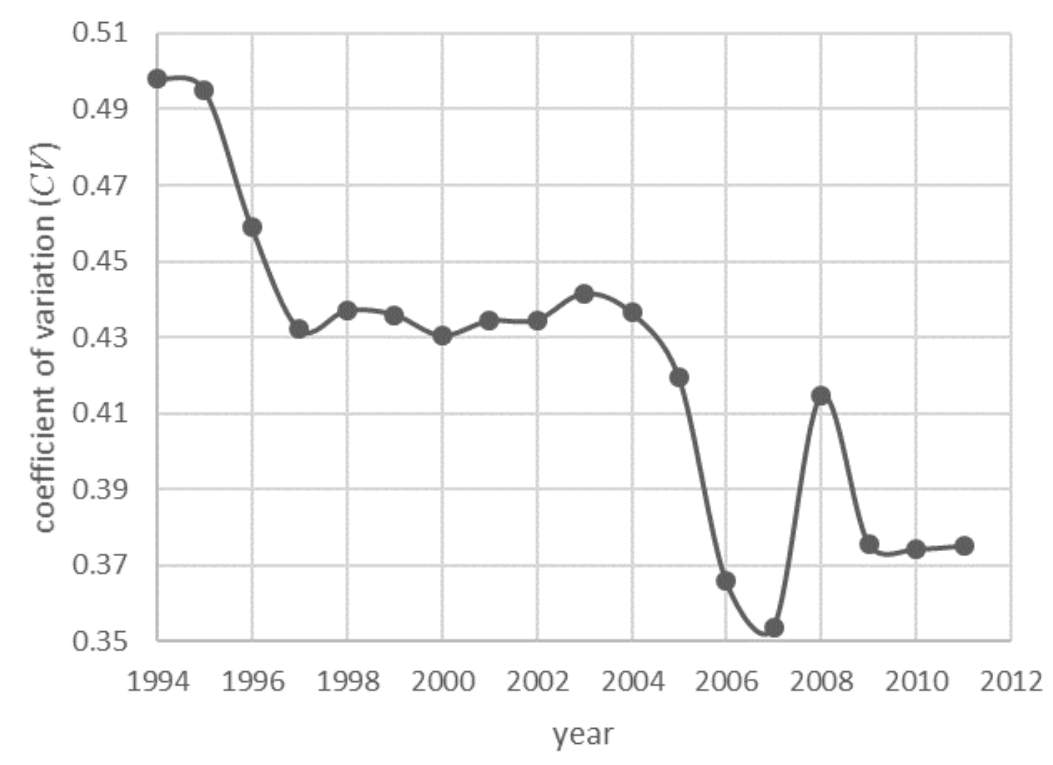

Figure 1. Trend of variable coefficient of China knowledge innovation from 1994 to 2011

Over 1994 to 2011, it can be seen that discrete degree of total paper numbers of interdisciplinary core journal presents a fluctuation, but the differences of the numbers of core periodical papers narrowed sharply after 1994 and 2003, so it can be thought that the numbers of the core journal papers appeared to sigma - convergence from 1994.

This is consistent with China's policy environment at that time. It was the time of education industrialization and great leap forward from 1990 to 2003. During that period, China's education took expansion in scale, total growth as the main target. Government used the market mechanism to expand education scientific research resources and encouraged schools and scientific research units to maintain profit. Different disciplines developed rapidly, thus, with the result that the coefficient of variation in this stage falls sharply for the first time. Great changes have taken place in the public policy of Chinese education and the idea of industrialization of education has been criticized since the second half of 2003. The main contents of public policy in this period are paying close attention to rural education, compulsory education and educational equality. Besides, it requires the education administrative departments at all levels to counteract effectively this trend of the expansion of 
education gap between urban and rural areas. This policy change has raised the enthusiasm of scholar about knowledge innovation. It is the reasonable explanation that coefficient of variation has fallen sharply for the second time begin in 2003. Affected by the earthquake in 2008, the differences between the different subjects had a huge fluctuations, and as the post-disaster reconstruction and the stability of people's life, the coefficient of variation leveled off gradually again.

Generally, the coefficient of variation showed a trend of decline gradually, therefore, the knowledge innovation presents a sigma - convergence overall.

\subsubsection{Beta - convergence analysis}

There is a negative correlation between the average annual growth rates of Interdisciplinary core journal papers and the initial total core journal papers in 1994 (correlation coefficient equal to - 0.2114).Furthermore, it may shows that there is a catch-up beta convergence for knowledge innovation in China from 1994 to 2011.

Using simplified Barro absolute beta convergence of linear regression equation for total interdisciplinary core journal papers from 1994 to 2011 by regression analysis, the measurement results are shown in table 2. It can be seen from the results that all the beta coefficient estimates are negative, so it supports the hypothesis that knowledge innovation in China between disciplines has a catch-up beta convergence.

Table 2. Regression results of beta convergence for China knowledge innovation (1994-2012)

\begin{tabular}{|c|c|c|c|c|c|c|}
\hline $\begin{array}{l}\text { lag phase } \\
\mathbf{k}\end{array}$ & $\begin{array}{l}\text { constant } \\
\text { c }\end{array}$ & & $\begin{array}{l}\text { coeffici ent } \\
\beta\end{array}$ & & $\mathbf{R}^{2}$ & p(F-stati sti cs) \\
\hline 1 & 0.2692 & $(1.3244)$ & -0.0211 & $(-1.0968)$ & 0.0071 & 0.2743 \\
\hline 2 & $0.5088 *$ & $(1.6714)$ & -0.0391 & $(-1.3491)$ & 0.0114 & 0.1792 \\
\hline 3 & $0.7021^{*}$ & (1.9474) & -0.0509 & $(-1.4794)$ & 0.0146 & 0.1412 \\
\hline 4 & 0.6467 & $(1.6287)$ & -0.0380 & $(-0.9982)$ & 0.0072 & 0.3199 \\
\hline 5 & $0.8255^{*}$ & $(1.8582)$ & -0.0474 & $(-1.1094)$ & 0.0095 & 0.2693 \\
\hline 6 & 1. $1103^{* *}$ & (2. 2599) & -0.0682 & $(-1.4376)$ & 0.0172 & 0.1532 \\
\hline 7 & 1. $5040^{* * * *}$ & $(2.7187)$ & $-0.1008^{*}$ & $(-1.8825)$ & 0.0318 & 0.0625 \\
\hline 8 & 1. $7385^{* * * *}$ & $(2.8357)$ & $-0.1165^{*}$ & $(-1.9547)$ & 0.0375 & 0.0535 \\
\hline 9 & 2. $0864^{* * *}$ & (3.1332) & $-0.1442^{* *}$ & $(-2.2219)$ & 0.0531 & 0.0289 \\
\hline 10 & $2.7648^{* * *}$ & (3. 7132) & $-0.2041 * * *$ & $(-2.807)$ & 0.0917 & 0.0063 \\
\hline 11 & 3. $3917 * * *$ & (3.938) & - 0. 2609*** & $(-3.0947)$ & 0.1235 & 0.0029 \\
\hline 12 & 3. $6936 * * *$ & $(4.1952)$ & $-0.2833^{* * *}$ & $(-3.2785)$ & 0.1563 & 0.0018 \\
\hline 13 & 3. $0943^{* * *}$ & (3.6048) & - 0. 2193** & $(-2.5977)$ & 0.1233 & 0.0124 \\
\hline 14 & 3. $1576^{* * *}$ & (3. 3171) & $-0.2242^{* *}$ & $(-2.3969)$ & 0.1313 & 0.0216 \\
\hline 15 & 3. $6568 * * *$ & (3. 2154) & - 0. 2757** & $(-2.4728)$ & 0.1792 & 0. 0197 \\
\hline 16 & 3. $8535^{* *}$ & $(2.6464)$ & - 0. 2991** & $(-2.1064)$ & 0.1978 & 0.0495 \\
\hline
\end{tabular}

Note: *,** and $* * *$ mean that the statistic significant is under $10 \%, 5 \%$ and $1 \%$ levels respectively; The round brackets are the $\mathrm{t}$ statistic test values and the same below.

When the beta convergence is examined in a short-term $(\mathrm{k}=1,2 \ldots 8)$, the beta estimates can't pass the $t$ test from 1997 to 2011, but the correlation is negative, meaning that the absolute beta convergence of knowledge innovation is not obvious in the short term; When the beta convergence is examined in a long-term $(\mathrm{k}=9,10, \ldots, 16)$, the beta estimates can pass the $\mathrm{t}$ test and F test with the significant level of 5\% from 1997 to 2011, so it can be concluded that the knowledge innovation in China presents an absolute beta convergence in long-term. 
Considering the fields of liberal arts (social sciences, four disciplines including philosophy, politics, military and law, education and social science synthesis and economics and management) and science (natural science, six disciplines including Mathematics Physics Mechanics Astronomy Biology Geography, Chemistry and Chemical industry Metallurgy Environment Mining, Electro mechanics Aviation Traffic Water conservation Building Energy, agriculture, Medicine Health, and Electronic technology Information Science), here introduce the concept of convergence clubs to inspect whether the internal club convergence presents a beta convergence or not The empirical analysis results are shown in table 3.

Table 3, beta convergence regression results of knowledge innovation in China (1994-2012)

\begin{tabular}{|l|l|l|l|l|}
\hline & \multicolumn{2}{|l|}{ arts } & \multicolumn{2}{l|}{ science } \\
\hline & $\mathrm{k}=3$ & $\mathrm{k}=13$ & $\mathrm{k}=3$ & $\mathrm{k}=13$ \\
\hline $\mathrm{c}$ & 0.5957 & $1.4502 * * *$ & $1.0173^{*}$ & $5.3956^{* * *}$ \\
& $(1.1948)$ & $(3.0247)$ & $(1.9942)$ & $(4.6044)$ \\
\hline$\beta$ & -0.0450 & -0.0722 & -0.0780 & $-0.4347 * * *$ \\
& $(-0.9374)$ & $(-1.5247)$ & $(-1.611)$ & $(-3.7844)$ \\
\hline $\mathrm{R}^{2}$ & 0.0149 & 0.1144 & 0.0286 & 0.3384 \\
\hline
\end{tabular}

As it can be seen from the results that in the short run $(\mathrm{k}=3)$, the results of beta estimate are negative and not significant. Namely, the beta convergence of liberal arts and sciences are both not significant in the short term. While in the long run $(\mathrm{k}=13)$, beta estimates of arts are negative and the $t$ statistic is not significant; however, science has a negative beta estimate and a significantly t statistic, showing that science knowledge innovation presents an obvious beta convergence over the long term.

\subsubsection{An empirical study of interaction between knowledge innovation and economy}

The above conclusions is further verified by granger causality test, as shown in the following table. The causality test is extremely significant and rejects the null hypothesis at the $5 \%$ significance level. Namely, the variables of GDP and PN are granger causality mutual.

Table 3, the results of granger causality test

\begin{tabular}{|l|l|l|l|}
\hline null hypothesis & F- statistic & significance probability & conclusion \\
\hline Variables GDP is not a granger cause of PN & 18.93 & 0.0000 & $\begin{array}{l}\text { reject null } \\
\text { hypothesis }\end{array}$ \\
\hline Variables PN is not a granger cause of GDP & 8.568 & 0.0060 & $\begin{array}{l}\text { reject null } \\
\text { hypothesis }\end{array}$ \\
\hline
\end{tabular}

It can be seen from the results that there is a mutual influence between knowledge innovation and economy. It is the most important thing to create a good environment for knowledge innovation and suitable policy and system.

Therefore, to improve the economic potential growth Chine should attach great importance to knowledge innovation, increase the input for research accelerate the reform of economic system.

\section{Conclusion and Advice}

According to the above empirical analysis, the conclusions are as follows:

(1) GDP growth contributes to the growth of the knowledge innovation, but the increment speed of knowledge innovation is slower than the increment speed of GDP, so that knowledge innovation in China lags behind developed countries in the perspective of scale and economic transformation. It demonstrates that the scale of knowledge innovation is not enough and does not adapt to the goals of powerful science and technology. In order to meet the needs of 
knowledge innovation, it is imperative that the government should strengthen the input for education and scientific research.

(2) Chinese interdisciplinary knowledge innovation showed a sigma - convergence since 2004.It was consistent with the change of China education after 2003 and the initiatives of the public policy of research. At the same time, there is no beta convergence in interdisciplinary knowledge innovation in short-term between 1994 and 2011. Nevertheless, there is an absolute beta convergence in a long term showing the obvious characteristics of catch-up. The 16th Party Congress proposed the principle of adhering to the priority to the development of education and education equity, China transforms the public policy of education and scientific research, increase the investment of scientific research gradually. However, the increment speed of knowledge innovation is far lower than the increment speed of the economic indicating that the knowledge innovation scale still needs to be increased.

(3) Financial governments should take precedence to ensure the investment for education and scientific research at various levels. Government entities should optimize of fiscal expenditure structure and guarantee the fiscal expenditure in scientific research. Government should perfect innovation mechanism and encourages the potential of schools, scientific research units, enterprises, social organizations and individuals

(4) Rationally allocate the education resources, facilitate educational equality, and exert the positive effect of industrial associations, foundations and financial organizations on knowledge innovation.

\section{Acknowledgement}

The research is financed by College of Economics and Management, Sichuan Agricultural University. Thanks for the anonymous reviewers.

\section{References}

You, Z., \& Jian-hui, Z. (2012). Long-wave theory, innovation and analysis of Chinese business cycle. Economic Theory and Business Management, 2012 (5), 21-26.

Ji, M. (2011). The knowledge innovation and regional economic growth - a spatial econometric testing framework. Journal of Southwest University for Nationalities (Humanities and Social Science), 2011 (4), 137-143.

SIPO. (2013). The organization for economic co-operation and development issued a report analyzing the trend of global knowledge and innovation and developmen [WWW page]. URL http://www.ipr.gov.cn/guojiiprarticle/guojiipr/guobiebh/gjjgzz/201111/1264399_1.html.

Menguc, B., Auh, S., \& Uslu, A. (2013). Customer knowledge creation capability and performance in sales teams. Journal of the Academy of Marketing Science, 41 (1), 19-39.

Zhen, L. (2012). The research of the trend of total financial expenditure on education and the trend of changes in the structure. Journal of Central University of Finance \& Economics, 2012 (11), 1-6.

\section{Glossary}

CJFD: Chinese Journal Full-text Database. 